\title{
JOINT PRICING DETERIORATING INVENTORY MODEL CONSIDERING PRODUCT LIFE CYCLE AND ADVANCE PAYMENT WITH A DISCOUNT FACILITY
}

\author{
Abu Hashan Md Mashud ${ }^{1}$, Dipa Roy ${ }^{1}$, Yosef Daryanto ${ }^{2}$ and Hui-Ming Wee ${ }^{3, *}$
}

\begin{abstract}
The product life cycle of a deteriorating product is an important consideration in inventory management. This paper simultaneously investigates the optimum pricing and inventory decisions considering product life cycles under price-dependent demand and advance payment systems with a discount facility. A time-dependent holding cost is also introduced. The objective is to carefully balance the critical decision variables in order to maximize the total profit. Furthermore, the theoretical analysis validates the concavity of the profit function. A numerical example and sensitivity analysis are provided to show the characteristics of the model. The study shows that an advanced payment period, installment numbers, product's maximum life cycle, purchasing cost and demand function significantly influence the total profit. This inventory model with a known product lifetime and advance payments can provide management insights to inventory manager in his/her strategic planning.
\end{abstract}

Mathematics Subject Classification. 90B05, 90B25, 90B60.

Received May 18, 2019. Accepted September 22, 2020.

\section{INTRODUCTION AND LITERATURE REVIEW}

Inventory management plays an important role in balancing uncertain customer demand and supply. Economic order quantity (EOQ) is a basic formula that helps businesses to minimize the total inventory cost. In recent decades, supply chain management has become very popular, and various inventory models considering the mutual relationship among supply chain parties have been developed. Most inventory models assumed immediate payment upon the receipt of a product. Goyal [7] introduced allowable delay-in-payments by the supplier in his EOQ model. Aggarwal and Jaggi [1] pointed out that permissible delay might be financially sustainable for buyers. Recently, Mashud et al. [24] examined the delay-in-payments policy for non-instantaneous deteriorating items with a plan to invest in preservation technology, while Mashud et al. [25] examined an inventory model for two different types of deterioration rates. Panda et al. [30] examined a trade-credit approach for a two warehouse problem while Mashud et al. [26] provided a two-level trade-credit approach with shortages.

Keywords. Advance payment, deterioration, inventory, product life cycle, price-dependent demand.

1 Department of Mathematics, Hajee Mohammad Danesh Science and Technology University, Dinajpur 5200, Bangladesh.

2 Department of Industrial Engineering, Universitas Atma Jaya Yogyakarta, Yogyakarta, Indonesia.

3 Department of Industrial and Systems Engineering, Chung Yuan Christian University, 200 Chung-Pei Rd., 32023 Chung-li, Taiwan.

${ }^{*}$ Corresponding author: weehm@cycu.edu.tw 
Advance payment is an alternative payment policy for suppliers. When a retailer places an order for the product, the supplier demands some money in advance. Next, the supplier provides some price discounts for advance payment. Lastly, a certain scheme allows the retailer to pay a part of the purchase cost by installments. Maiti et al. [22] incorporated an advance payment pattern, price-dependent demand and stochastic lead-time in their model. Gupta et al. [8] proposed a model with the retailers' advance payment to the wholesalers. Guria et al. [9] proposed an inventory procedure that allowed for an item's immediate payment for a random planning horizon. Taleizadeh [34] considered multiple prepayments for deteriorating items with shortages. Taleizadeh [35] developed an inventory pricing and replenishment model with advance payment and quality problems. Taleizadeh et al. [37] modified the previous model by considering complete backordering. Teng et al. [38] considered advance payment with a maximum products life cycle. Recently, Taleizadeh et al. [36] developed an incremental discount model while Khan et al. $[19,20]$ provided a cash discount for full purchase cost payment. Khan et al. [18,21] and Shaikh et al. [33] considered advance payment for a two-warehouse problem with partial backordering. However, none of these models offered a discount on multiple prepayments or considered the products' maximum lifetime.

In general, customer demand depends largely on the relative price of the product. Using a discounted cash flow method, Hou and Lin [11] developed a replenishment decision model for deteriorating items with price dependent demand. Hasan and Mashud [10] formulated an EOQ model with price, continuous-time, and frequency of advertisement dependent demand under a shortage policy. Dye and Hsieh [6] modified the model by permitting the demand rates affected by both the selling price and the displayed stock level. Yang et al. [42] introduced time and selling price-dependent demand rates while allowing multiple production cycles. Alfares and Ghaithan [2] developed a pricing inventory model showing a time-varying unit holding cost with a discount facility and a rented warehouse agreement. Shaikh et al. [31] acquainted an inflationary inventory model, under which non-instantaneous deterioration and fully backlogged shortages were considered for a price and stockdependent demand pattern. Mashud [23] considered different price-sensitive demand patterns and developed inventory models with shortages, while Mashud et al. [27] anticipated a model with the same demand pattern and controlling the deterioration rate through preservation technology investment under a credit policy. Jadidi et al. [16] considered price-dependent stochastic demand with all-unit quantity discounts and the effect of transportation. Chen et al. [5] optimized the discount strategy of an inventory model with an unknown customer demand distribution. Later, Shaikh et al. [32] framed a temporary discount EOQ model where shortages were allowed with stock-dependent demand and time-varying deterioration rates. They provided a discount facility for a backorder inventory model with time reliant deterioration, but did not consider an advance payment scheme, while Mashud et al. [28] considered advance payment with discount facility on prepayments.

In many situations, deterioration is a common occurrence. Deteriorating items, such as vegetables, fruits, flowers, and ice cream, are decayed, damaged, or expire over time. The lifetime of deteriorating items is limited, and these items have an expiration date. Specifically, the rate of deterioration rises over time and the items will totally degrade at the expiration date. Therefore, to develop an inventory strategy, the rate of deterioration should be taken into account. Researchers studied some extended models for declining items with an expiration date or maximum lifetime. Wu et al. [41] considered the expiration dates of declining products, in which the deterioration rate function approaches the full item value near the expiration date. Later, Chen and Teng [3] settled an EOQ model for a retailer where the product has a continuous deterioration, a maximum lifetime, and simultaneously, uses a trade-credit approach. Considering the seller's optimal credit period and the product's maximum lifetime, Wang et al. [40] examined the cycle time for deteriorating items. Extending the concept of Wu et al.'s [41], Tiwari et al. [39] delivered a supply chain inventory model with an expiration date to determine the optimum price and replenishment cycle. A new concept was introduced by Teng et al. [38] by simultaneously considering advance payments and a 100\% decay rate at the product expiration date. Chen et al. [4] projected an EOQ model by considering demand for fresh products, which depend on their fresh-ending date and current inventory while Pal et al. [29] projected an inventory model with a stochastic production rate and production cost with a fixed lifetime. Many researchers took a price-sensitive demand pattern with a constant deterioration rate, but very few considered the product life cycle. Iqbal and Sarkar [12] considered a price-dependent demand that is influenced by the product's maximum lifetime. Iqbal and Sarkar [13] considered a deterioration rate that 
TABLE 1. The distinction between previously established research and the current work.

\begin{tabular}{lllllll}
\hline \hline Authors & Demand & $\begin{array}{l}\text { Holding } \\
\text { cost }\end{array}$ & $\begin{array}{l}\text { Payment } \\
\text { mode }\end{array}$ & Deterioration & Discount & $\begin{array}{l}\text { Maximum } \\
\text { lifetime }\end{array}$ \\
\hline Aggarwal and Jaggi [1] & CN & CN & DL & CN & No & No \\
Hou and Lin [11] & PD \& SD & CN & No & CN & No & No \\
Maiti et al. $[22]$ & PD & CN & AV & No & No & No \\
Gupta et al. $[8]$ & CN & CN & AV & No & Yes & No \\
Dye and Hsieh [6] & PD \& SD & CN & No & CN & No & No \\
Chen and Teng [3] & CN & CN & DL & TV & No & Yes \\
Taleizadeh [34] & CN & CN & AV & CN & No & No \\
Wang et al. $[40]$ & CPD & CN & DL & EXP & No & Yes \\
Wu et al. $[41]$ & CN & CN & DL & EXP & No & Yes \\
Alfares and Ghaithan $[2]$ & PD & TV & No & No & Yes & No \\
Chen et al. $[4]$ & SD & CN & No & EXP & No & Yes \\
Teng et al. $[38]$ & CN & CN & AV & TV & No & Yes \\
Shaikh et al. $[31]$ & PD \& SD & CN & No & CN & No & No \\
Tiwari et al. $[39]$ & PD & CN & DL & EXP & No & Yes \\
Shaikh et al. $[33]$ & PD \& SD & TV & No & CN & No & No \\
Khan et al. $[20]$ & PD \& SD & CN & AV & CN & Yes & No \\
This article & PD & CN \& TV & AV & EXP & Yes & Yes \\
\hline
\end{tabular}

Notes. Where AV: Advance, DL: Delay, CN: Constant, PD: Price-sensitive, CPD: Credit-period dependent, EXP: Expiration, TV: Time-varying. SD: Stock-dependent.

depends on time and its maximum lifetime. Recently, Iqbal and Sarkar [14] studied deteriorating items with lifetime-reliant demand rate and incorporated the consequence of preservation technology. Some of the main contributions of the projected model are as follows:

(i) This paper extends the idea of Teng et al. [38] by incorporating a realistic holding cost and discount incentive for multiple prepayments.

(ii) This model provides a new idea in discount policy with multiple prepayments which will extend the idea of instant cash discount on purchase cost anticipated in Khan et al. [20].

(iii) The proposed model will simultaneously examine pricing effects with an advance payment system and a product life cycle.

This article presents an EOQ model considering the maximum lifetime of a decaying item. The deterioration rate increases over time and the products are totally deteriorated at the time of expiration. At the end of the product lifetime, the product has no salvage value. The retailer prepays a portion of his purchase cost as an advance through equal multiple installments to the supplier before receiving the products. The proposed model works under selling price-dependent demand, and the holding cost is a linear function consisting of constant and time-varying components. Table 1 summarizes the distinction between some related works.

Following the introduction in Section 1, Section 2 represents all the notations and model assumptions. Section 3 explains the development of the model. Section 4 presents some theoretical derivations from the basic model. Section 5 provides some numerical examples and sensitivity analysis in Section 6. Section 7 discusses some important managerial insights. In the end, Section 8 summarizes the findings and proposes some future works. 


\section{Notation AND ASSUMPtions}

\subsection{Notation}

With the help of the following notations, the proposed model is constructed.

\begin{tabular}{lll}
\hline Notations & Units & Description \\
\hline$p_{c}$ & $\$ /$ unit & purchasing cost of products per unit \\
$h_{c}$ & $\$ /$ unit/unit time & cost of holding product per unit per unit time \\
$\theta(t)$ & per year & deterioration rate $(0 \leq t \leq m)$ \\
$I(t)$ & Units & inventory level \\
$D$ & Units & demand rate \\
$O$ & $\$ /$ order & ordering cost per order, $O>0$ \\
$H$ & $\$ /$ cycle & holding cost per cycle \\
$A$ & $\$ /$ cycle & purchase cost per cycle \\
$C$ & $\$ /$ cycle & capital cost per cycle \\
$S$ & Units & the initial level of inventory \\
$Q$ & Units & quantity of products ordered by the retailer \\
$L$ & Years & the time range for the retailer to pay in advance where, $L>0$ \\
$r$ & $\$ /$ unit & the rate of interest imposed on capital cost per year \\
$n$ & Integer & number of equal prepayments \\
$u$ & $\$ /$ unit & constant factor of holding cost \\
$v$ & $\$ /$ unit & time reliant factor of holding cost \\
$x$ & $\%$ & discount rate for a single installment of the prepayment \\
$I_{r}$ & $\$ /$ unit & rate of interest on the loan \\
$m$ & years & the expiration date of products, $0<m<8$ \\
$\beta$ & $\%$ & discount on purchase cost for prepayments \\
$\gamma$ & $\%$ & a portion that the retailer has to prepay from the purchase cost before receiving \\
$a$ & Constant & the products, $0 \leq \gamma \leq 1$ \\
$b$ & Constant & a constant factor in demand function, $a>0$ \\
Decision & price reliant factor in demand function, $b>0$ \\
\hline$p$ & $\$ /$ unit & the price of selling products \\
$T$ & years & the cycle length of the proposed model \\
\hline & &
\end{tabular}

\subsection{Assumptions}

The succeeding assumptions have been considered for the advance of the model.

1. A linear price-sensitive demand $D=(a-b p)$, represents the customer demand that increases when the price of products decreases. Thus, $D$ is a linearly decreasing function of the selling price, $p ; a$ and $b$ are constants greater than zero. The demand $D$ is non-negative with constraint $a>b p$ [39].

2. The deterioration rate of the perishable products is time dependent. All the deteriorating items deteriorate over time and salvage at the expiration date $m$, i.e., $0 \leq \theta(t) \leq 1$ which satisfies $\theta^{\prime}(t)<0$ and $\theta(m)=1$. Using the same assumption of Chen and Teng [3], Wang et al. [40] and Teng et al. [38], one has:

$$
\theta(t)=\frac{1}{1+m-t}, \quad 0 \leq t \leq T \leq m .
$$

3. No option for a replacement or repair is considered in the proposed model for the deteriorated items.

4. The lead time is constant.

5. There is no shortage allowed.

6. On behalf of the extremely seasonal and deteriorating items, the supplier demands a certain percentage of the retailer's purchase cost prepayments. The remaining balance is paid upon delivery of the purchase [34]. 


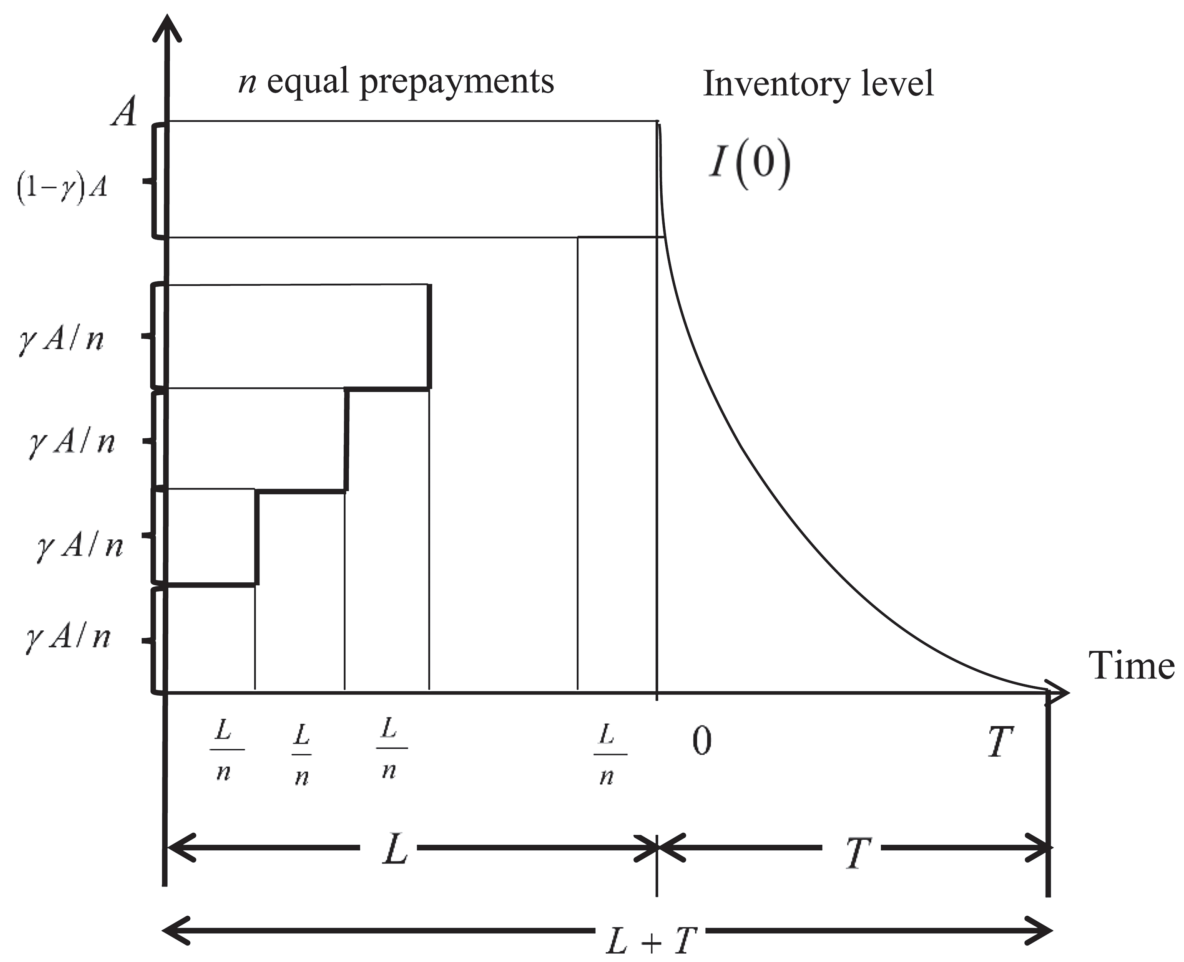

FiguRe 1. A graphical framework of the proposed model.

7. In terms of the prepayments, the supplier also offers a discount on purchased products. To receive the discount, the retailer accepts the condition and pays $\gamma A$ on $n$ equal prepayments during $L$ years before delivery (see [20]).

\section{Mathematical Formulation}

We have discussed two models with advance payments. The first case assumes that the payment is completed in several equal installments. Later, in the second case, the retailer borrows some money for his purchase cost from any financial institution to prepay the whole cost at a formerly determined time, receiving the products and enjoying a cash discount on that amount.

\subsection{Case 1 (Discount when payment is paid in installments)}

Figure 1 indicates the EOQ model where the retailer is bounded to $n$ equal prepayments before the order delivery, and then the rest of the purchase cost must be completed at the time of delivery. When the full payments are done, the level of retailer's inventory $I(t)$ starts with $S$ units, and then due to both demand and deterioration, it starts to decrease and gradually reaches zero at $t=T$.

Throughout the replenishment cycle $[0, T]$, the inventory level at time $t$ is ascertained by the subsequent differential equation:

$$
\frac{\mathrm{d} I}{\mathrm{~d} t}+\theta(t) I(t)=-D, \quad 0 \leq t \leq T
$$

where $D=a-b p$ and $\theta(t)=\frac{1}{1+m-t}, 0 \leq t \leq m$.

Assuming the boundary conditions $I(0)=S$ and $I(T)=0$. 
By using the boundary conditions, we solve equation (3.1), and the obtained solution is

$$
I(t)=D(1+m-t) \ln \left(\frac{1+m-t}{1+m-T}\right) .
$$

At $t=0, I(t)=S$. Then from equation (3.2), we get

$S=D \varphi$, where $\varphi=(1+m) \ln \left(\frac{1+m}{1+m-T}\right)$.

Therefore

$$
Q=S=D \varphi .
$$

The retailer's sales revenue refers to the income derived from product sales. If $p$ is the product's selling price, $a$ is the constant part and $b$ is the coefficient of price in demand, then the sales revenue can be written as

$$
\mathrm{SR}=p \int_{0}^{T} D \mathrm{~d} t=p D T .
$$

The cost of placing an order of products per cycle can be written as

$$
\mathrm{OC}=O
$$

If $p_{c}$ is the purchasing cost per unit of product and $Q$ be the ordered quantity, then the purchasing cost per cycle can be written as

$$
A=p_{c} Q=p_{c} D \varphi .
$$

After purchasing the products, the retailer has to store them for a certain period. The holding cost $(H)$ includes the costs of storing products such as rent, labor, and utilities. The cost of holding some products varies over time as their freshness depends on time. If $h_{c}$ is the cost of holding product per unit per unit time, $u$ and $v$ are the constant and time reliant factor of holding cost, then the $H$ per cycle:

$$
\begin{aligned}
H & =h_{c} \int_{0}^{T}(u+v t) I(t) \mathrm{d} t \\
& =h_{c} D\left[\begin{array}{l}
u\left\{\frac{(1+m)}{2} \varphi+\frac{1}{4}\left(-2 T-2 m T+T^{2}\right)\right\} \\
+v\left\{\frac{1}{36}\left((1+m-T)^{2}(5+5 m+4 T)-5(1+m)^{3}\right)+\frac{(1+m)^{2}}{6} \varphi\right\}
\end{array}\right] .
\end{aligned}
$$

As the supplier requests the retailer to pay advance before delivery, the retailer prepays $\gamma$ fraction of his purchase cost $A$ in $n$ number of equal installments before delivery. Agreeing to Taleizadeh [35], the capital cost for per cycle can be written as,

$$
C=r\left[\frac{\gamma A}{n}\left(\frac{L}{n}\right)(1+2+\ldots+n)\right]=\left(\frac{n+1}{2 n}\right) \gamma \operatorname{Lr} A=\left(\frac{n+1}{2 n}\right) \gamma \operatorname{Lrp}_{c} D \varphi .
$$

To receive the maximum $x$ percent discount on product purchases, the retailer must pay some portions of his purchase costs in $n$ number of equal installments before delivery. The relationship between the discount rate $\beta$ of the purchase cost and the number of prepayments $n$ is

$$
\beta=\frac{x}{n}, \quad 0 \leq x \leq 100 .
$$

The discount on prepayments (DC) can be written as:

$$
\mathrm{DC}=p_{c} Q \beta=\frac{x p_{c}}{n} D \varphi .
$$




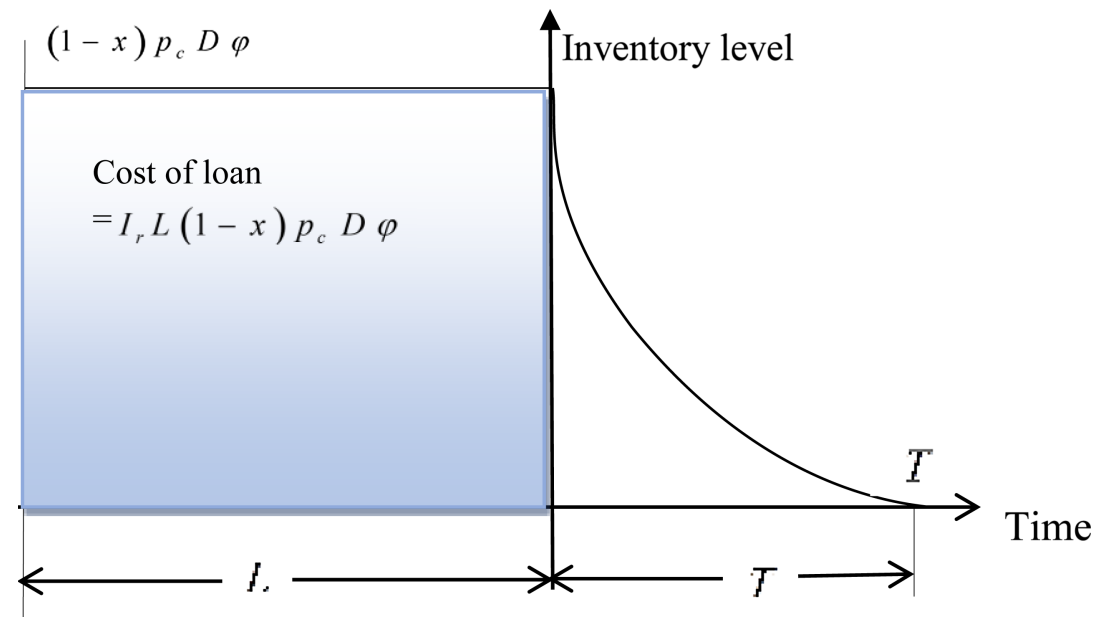

FIGURE 2. A pictorial representation when payment is done at a time.

Total profit per cycle written as a function of total cycle length $T$ and selling price $p$ is as follows:

$$
\begin{aligned}
\psi(p, T) & =\frac{1}{T}(\mathrm{SR}-\mathrm{OC}-A-C-H+\mathrm{DC}) \\
& =\frac{1}{T}\left\{\begin{array}{l}
p D T-O-p_{c} D \varphi\left[1+\left(\frac{n+1}{2 n}\right) \gamma L r-\frac{x}{n}\right] \\
-h_{c} D\left[\begin{array}{l}
u\left\{\frac{(1+m)}{2} \varphi+\frac{1}{4}\left(-2 T-2 m T+T^{2}\right)\right\} \\
+v\left\{\frac{1}{36}\left((1+m-T)^{2}(5+5 m+4 T)-5(1+m)^{3}\right)+\frac{(1+m)^{2}}{6} \varphi\right\}
\end{array}\right]
\end{array}\right.
\end{aligned}
$$

\subsection{Case 2 (Discount when payment is paid at a time)}

Figure 2 indicates a situation where the retailer offers $x \%$ discount to the customer for complete advance payment before delivery [20]. When it is the buyer does not have enough fund during the time $L$, he may take a loan from a bank at an interest rate of $I_{r} \%$.

The purchased cost with discount can be written as

$$
A=(1-x) p_{c} D \varphi
$$

The cost of taking a loan can be written as

$$
G=I_{r} L(1-x) p_{c} D \varphi
$$

Then the total profit becomes

$$
\begin{aligned}
\psi(p, T) & =\frac{1}{T}(\mathrm{SR}-\mathrm{OC}-A-H-G) \\
& =\frac{1}{T}\left\{\begin{array}{l}
p D T-O-\left(1+I_{r} L\right)(1-x) p_{c} D \varphi \\
-h_{c} D\left[\begin{array}{l}
u\left\{\frac{(1+m)}{2} \varphi+\frac{1}{4}\left(-2 T-2 m T+T^{2}\right)\right\} \\
+v\left\{\frac{1}{36}\left((1+m-T)^{2}(5+5 m+4 T)-5(1+m)^{3}\right)+\frac{(1+m)^{2}}{6} \varphi\right\}
\end{array}\right]
\end{array}\right.
\end{aligned}
$$




\section{THEORETICAL DERIVATION}

In this section, the theoretical derivations of the stated two cases are discussed. In Section 4.1, the theoretical derivation for Case 1 is derived whereas Section 4.2 stands for Case 2.

\subsection{Case 1}

To get the optimal solution $T^{*}$, performing the first and second-order partial derivatives of $\psi(p, T)$ in $(3.10)$ with regard to $T$ and re-arranging terms, one has

$$
\begin{aligned}
\frac{\partial \psi}{\partial T}= & \frac{O}{T^{2}}+p_{c} D \mu_{1}\left(1+\frac{n+1}{2 n} \gamma L r-\frac{x}{n}\right) \\
& +h_{c} D\left[\frac{u}{4}\left\{2(1+m) \mu_{1}-1\right\}+v\left\{\frac{1}{36 T^{2}}\left(5 \mu_{2}-5 \mu_{3}-2 \mu_{4} T\right)-\frac{(1+m)^{2}}{6} \mu_{1}\right\}\right]
\end{aligned}
$$

where $\mu_{1}=(1+m)\left\{\frac{1}{T^{2}} \ln \left(\frac{1+m}{1+m-T}\right)-\frac{1}{T(1+m-T)}\right\}, \mu_{2}=(1+m)^{3}, \mu_{3}=(1+m)(1+m-T)^{2}$ $\mu_{4}=(1+m-T)(5+5 m+4 T)$

and

$$
\begin{aligned}
\frac{\partial^{2} \psi}{\partial T^{2}}= & -\frac{2 O}{T^{3}}-p_{c} D(1+m)\left(1+\frac{n+1}{2 n} \gamma L r-\frac{x}{n}\right)\left[\frac{2}{T^{3}} \ln \left(\frac{1+m}{1+m-T}\right)-\frac{2+2 m-3 T}{(1+m-T)^{2} T^{2}}\right] \\
& -h_{c} D\left[\begin{array}{l}
u(1+m)^{2}\left\{\frac{1}{T^{3}} \ln \left(\frac{1+m}{1+m-T}\right)-\frac{2+2 m-3 T}{2 T^{2}(1+m-T)^{2}}\right\} \\
+v\left\{\frac{(1+m)^{3}}{6}\left(\frac{2}{T^{3}} \ln \left(\frac{1+m}{1+m-T}\right)-\frac{2+2 m-3 T}{(1+m-T)^{2} T^{2}}\right)+\frac{10}{9} \frac{(1+m)^{3}}{T^{3}}-\frac{2}{9}\right\}
\end{array}\right] .
\end{aligned}
$$

From equations (4.1) and (4.2), we get the following theoretical results. By using (4.1), we define the following discrimination term:

$$
W=2 O-p_{c} D(1+m) \eta_{1}\left(1+\frac{n+1}{2 n} \gamma L r-\frac{x}{n}\right)-\frac{h_{c} D}{2}\left[\frac{u \eta_{2}}{2}-\frac{v \eta_{3}}{3}\right]
$$

where $\eta_{1}=[m-\ln (1+m)], \eta_{2}=\left[m^{2}-2(1+m)^{2} \ln (1+m)+2 m(1+m)^{2}\right], \eta_{3}=(1+m)^{3}\{m-\ln (1+m)\}+$ $\frac{1}{6}\left\{5(1+m)^{3}-5(1+m)-2 m(5+9 m)\right\}$.

Theorem 4.1. When $\frac{(1+m-2 T)}{(1+m-T)^{2} T}\left[p_{c} D\left(1+\frac{n+1}{2 n} \gamma L r-\frac{x}{n}\right)+\frac{h_{c} D(1+m)}{6}\{3 u+v(1+m)\}\right]<0$, foranygivenp $\geq 0$, then the obtained results are:

(a) $\psi(p, T)$ is maximized at $T^{*}=m$ when $W \geq 0$.

(b) When $W<0$, there exists a unique $T^{*}$ for which $\psi(p, T)$ is maximized at $(0, m)$.

Proof. Please see Appendix A.

To obtain the optimal cycle time $T^{*}$, we perform the first-order partial derivative of $\psi(p, T)$ in $(3.10)$ with regard to $T$. Then by determining the outcome to zero and rearranging the expressions,

$$
\begin{aligned}
\frac{O}{T^{2}} & +p_{c} D \mu_{1}\left(1+\frac{n+1}{2 n} \gamma L r-\frac{x}{n}\right) \\
& +h_{c} D\left[\frac{u}{4}\left\{2(1+m) \mu_{1}-1\right\}+v\left\{\frac{1}{36 T^{2}}\left(5 \mu_{2}-5 \mu_{3}-2 \mu_{4} T\right)-\frac{(1+m)^{2}}{6} \mu_{1}\right\}\right]=0 .
\end{aligned}
$$

Theorem 4.2. For any fixed $T>0$, the concavity of the function $\psi(p, T)$ exists in $p$ and gives a unique maximum solution $p^{*}$. 
Proof. See Appendix B.

To attain the optimal selling price $p^{*}$, we perform the first-order partial derivative of $\psi(p, T)$ in $(3.10)$ with regard to $p$. Then by determining the result to zero and rearranging the terms, we get

$$
\begin{aligned}
\frac{\partial \psi}{\partial p}= & (a-2 b p)+p_{c} b\left(1+\frac{n+1}{2 n} \gamma L r-\frac{x}{n}\right) \frac{1}{T} \varphi \\
& +h_{c} b\left[\begin{array}{l}
u\left\{\frac{(1+m)}{2 T} \varphi+\frac{1}{4}(-2-2 m+T)\right\} \\
+v\left\{\frac{1}{36 T}\left((1+m-T)^{2}(5+5 m+4 T)-5(1+m)^{3}\right)+\frac{(1+m)^{2}}{6 T} \varphi\right\}
\end{array}\right]=0 .
\end{aligned}
$$

Theorem 4.3. For any fixed $p>0$, the concavity of the function $\psi(p, T)$ exists in $T$ and gives a unique maximum solution $T^{*}$.

Proof. The proof is analogous to Theorem 4.2.

\subsection{Case 2}

To avoid the redundancy of the stated problem, we have omitted the theoretical derivation for Case 2. To understand the case's concavity, we have provided a three-dimensional graph (Fig. 6) and a numerical example (Example 2).

\section{Numerical illustration}

To demonstrate the model numerically, an algorithm together with some examples are given in this section and also gain some insights.

\subsection{Algorithm}

Step 1. For equation (4.3), use Lingo 17 software and input the initial parameters of $O$, a, $b, m, r, L, n, p_{c}$, $h_{c}, u, v$ and $\gamma$.

Step 2. Set $p$ to fixed.

Step 3. In equation (4.1) put $\frac{\partial \psi}{\partial T}=0$ for a critical point $T=T^{*}$.

Step 4. From equation (4.1), determine the discrimination term $W$.

Step 5. The maximum value of the function depends on the following two cases:
(a) If $W \geq 0$, then $T^{*}=m$.
(b) If $W<0$, then $T^{*} \in(0, m)$.

Step 6. Compute $\frac{\partial^{2} \psi}{\partial T^{2}}<0$ and then plug $T=T^{*}$ in this.

Step 7. If $\frac{\partial^{2} \psi}{\partial T^{2}}<0$, then maximum attained and Go to Step 8, otherwise no feasible solution found and Go to Step 9 .

Step 8. Putting the critical point $T=T^{*}$ in equation (3.10) to compute the maximum value of $\psi(p, T)$.

Step 9. Stop.

\subsection{Examples}

\section{Example 1. For case 1.}

A case is considered in this projected model, where a retailer secures an item for consumption from a supplier. To get a discount, the retailer prepays some portion of the purchase cost in advance, and the remainder is paid for at delivery. Because of customer demand and product degradation, the retailer's inventory decreases over time. The following parameters are considered:

Ordering cost, $O=\$ 500, a=60, b=0.1$, maximum life time, $m=5$ years, the rate of interest imposed on capital cost per year, $r=\$ 0.01$, lead-time of the chain, $L=0.5$ years, no of installments, $n=8$, purchase cost 


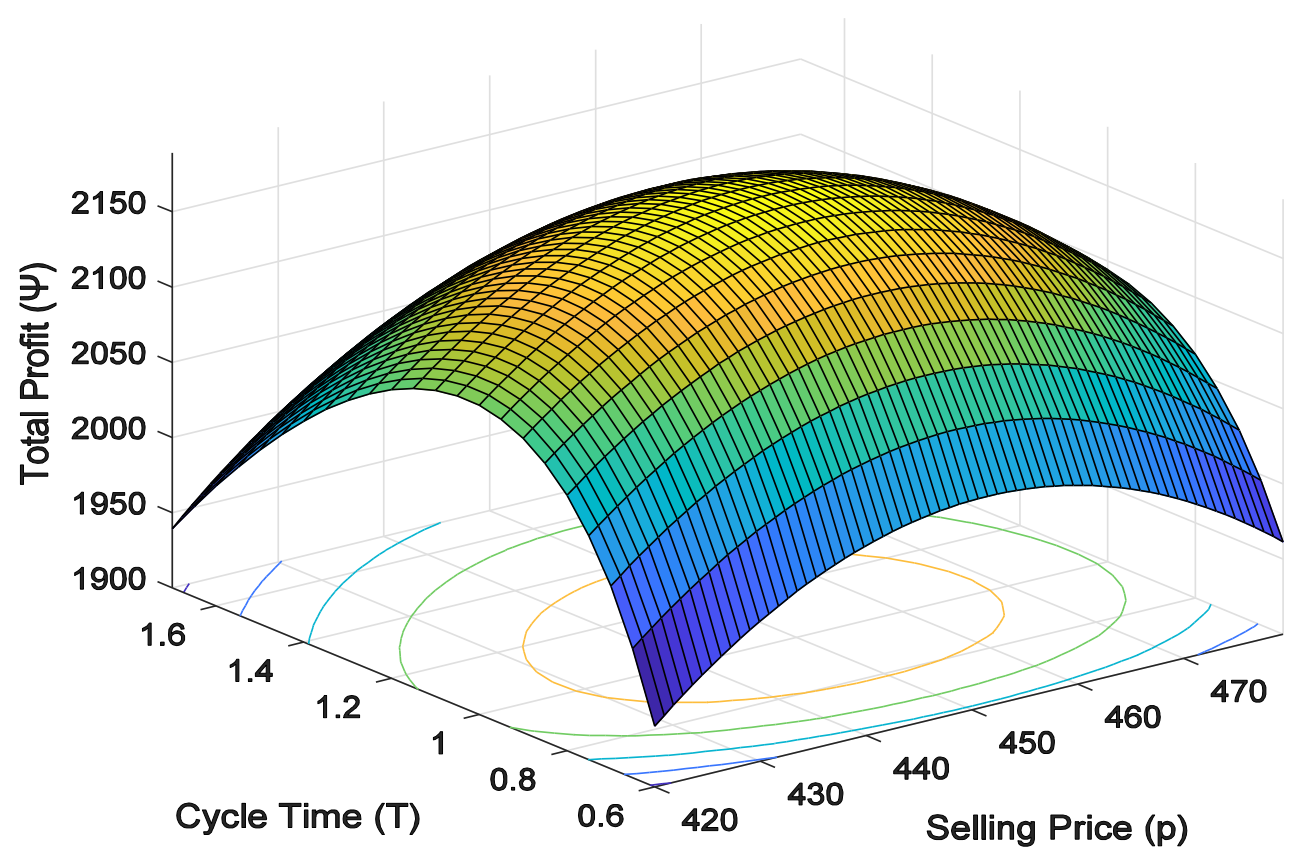

FiguRE 3. The concavity of $\psi(p, T)$ subject to decision variables.

to complete the order, $p_{c}=\$ 250$, holding cost for per unit products, $h_{c}=1$, constant part in holding cost per unit products, $u=2$, variable part in holding cost per unit products, $v=1$, discount rate, $x=\frac{1}{10}$, the amount which needs to be prepaid, $\gamma=0.2$.

By using these values we calculate: $\eta_{1}=3.208, \eta_{2}=255.993$ and $\eta_{3}=784.647$. Then, solving equation (4.3) by using Lingo 17 software, we get $W=-76693.958<0$. So, by Theorem 4.1 , there exists a unique $T^{*} \in(0, m)$, in which $\psi(p, T)$ is maximized. That means $T$ must belong to a range between 0 and 5 .

Now we get the following optimal solution after a calculation with the help of Lingo 17 software: $p^{*}=\$ 436.495$, $T^{*}=1.035$ years and $\psi^{*}=\$ 2190.435$.

Now, some graphs illustrate the concavity of the profit function. Figure 3 displays the 3D graph of $\psi(p, T)$ with regard to the variables $p$ and $T$, whereas Figures 4 and 5 represent it in a two-dimensional model.

\section{Example 2. For case 2.}

In this case, all the parameters are considered same as Example 1 except the discount rate, $x=0.33$, and the rate of interest imposed by a bank, $I_{r}=0.3$, and so we obtain the following optimal solution using Lingo 17 software:

The optimal values are: $p^{*}=\$ 406.813, T^{*}=1.075$ years and $\psi^{*}=\$ 3267.165$.

\section{Sensitivity AnAlysis}

The sensitivity investigation of the model presented in two sections; in the first section, we have introduced some graphs of some important parameters which have significant impacts on the models. In the second section, a table is given to show the elasticity of the model for the rest of the parameters. Taking the same values except for some variations in the time range for the retailer to pay in advance (prepayment time), Figures 7 and 8 show the variations of the profit function with the fluctuation of the value of prepayment time. It is noted from the figures that, with the increase in prepayment time, the profit of the system decreases significantly. This is 


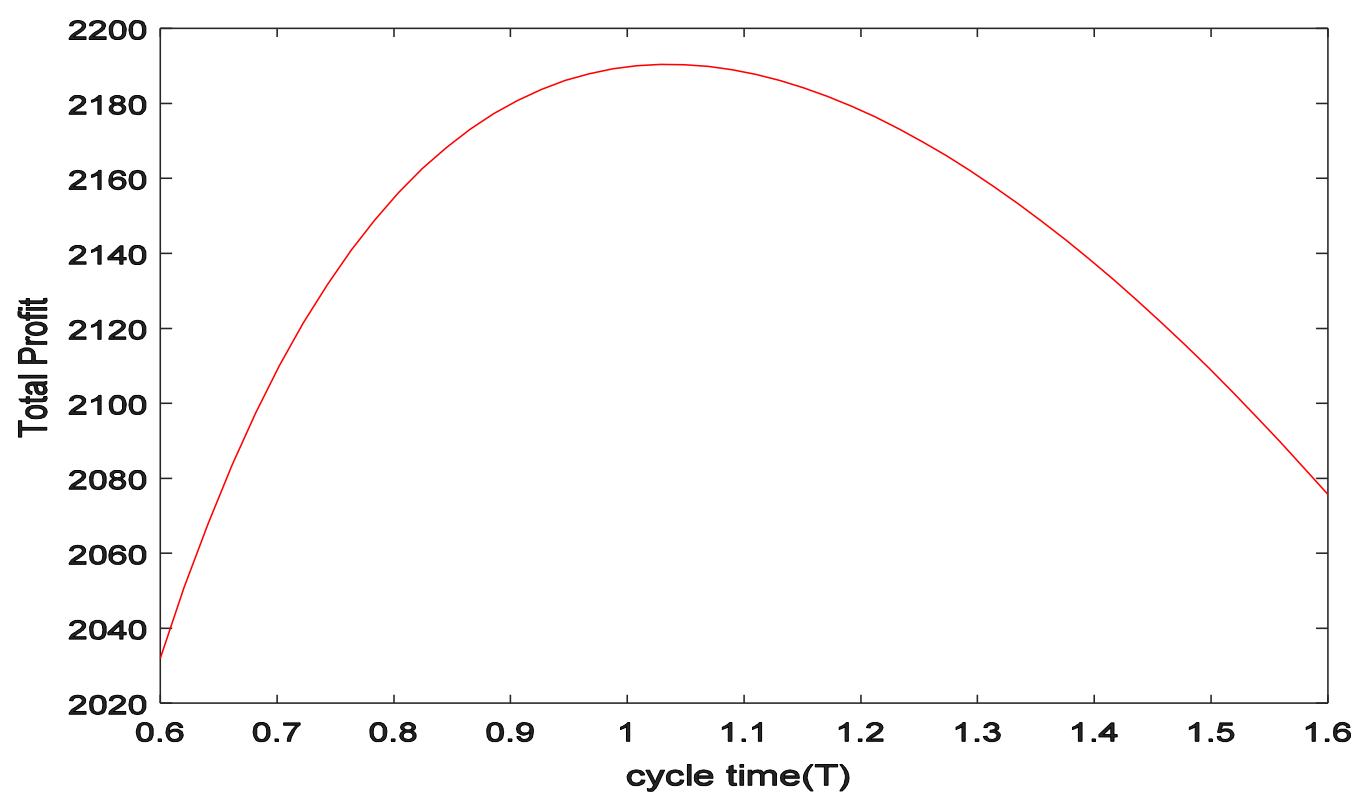

Figure 4. Total profit function subject to the cycle time $T$.

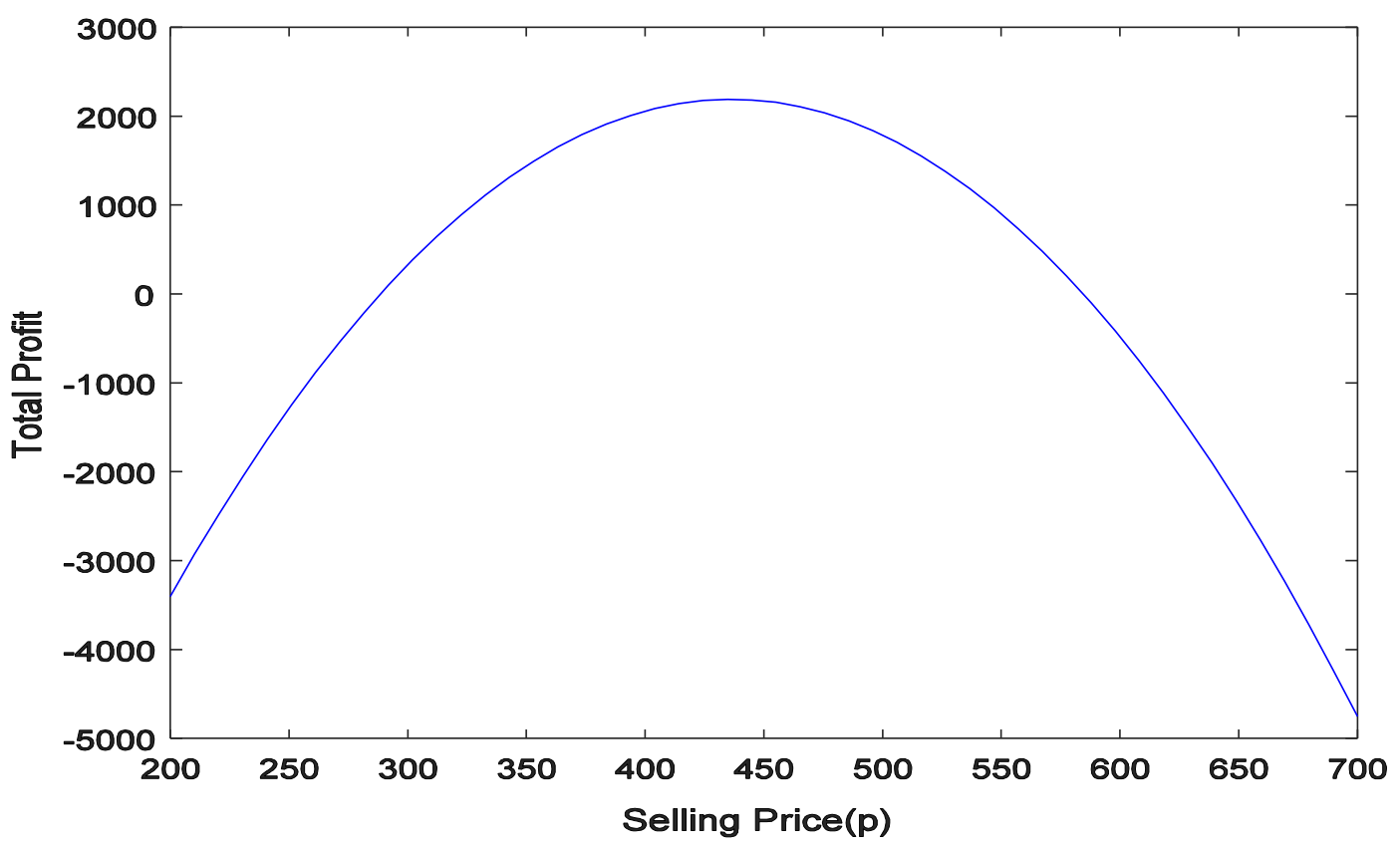

Figure 5. Total profit function subject to the selling price $p$. 


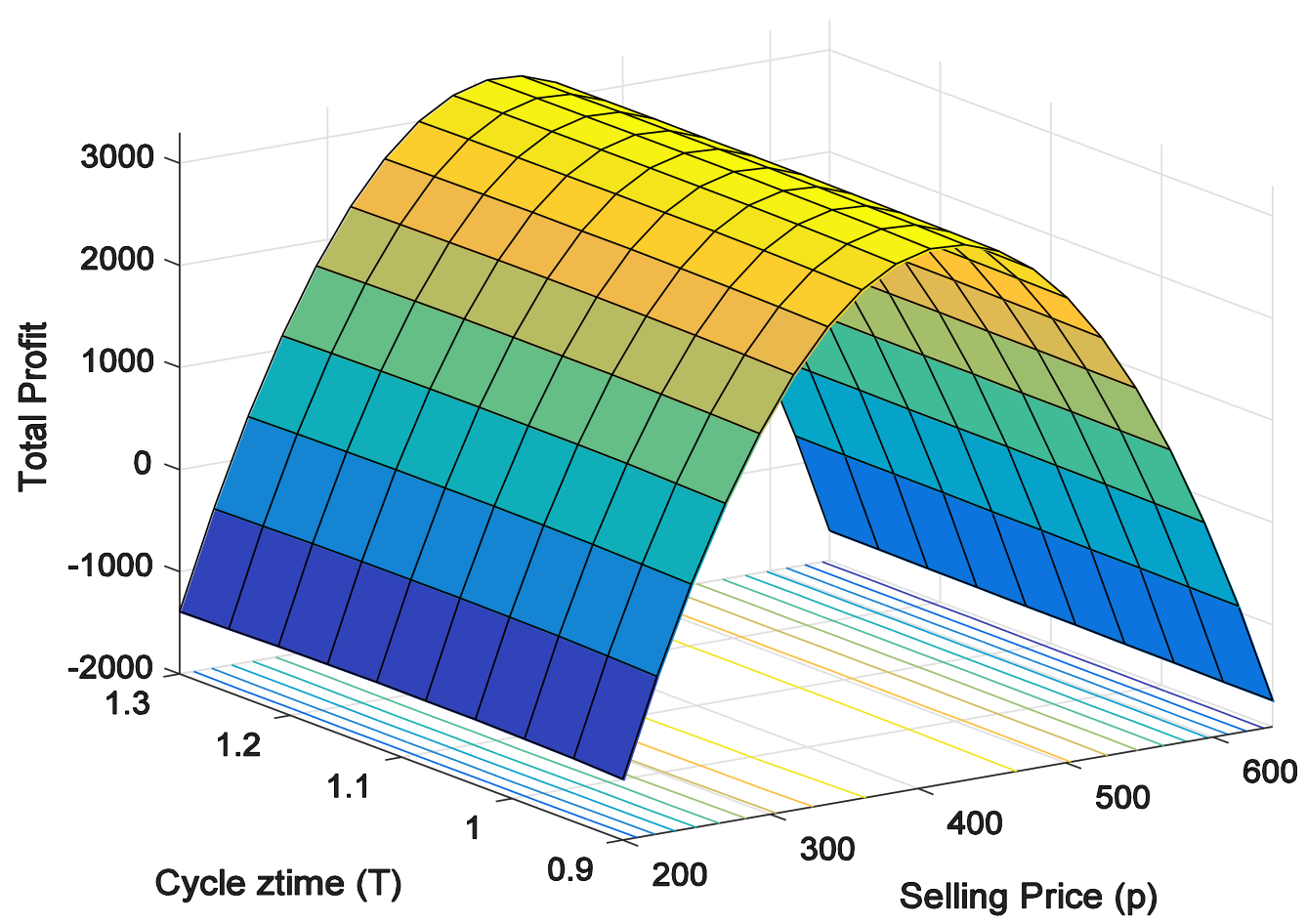

Figure 6 . The concavity of $\psi(p, T)$ subject to decision variables.

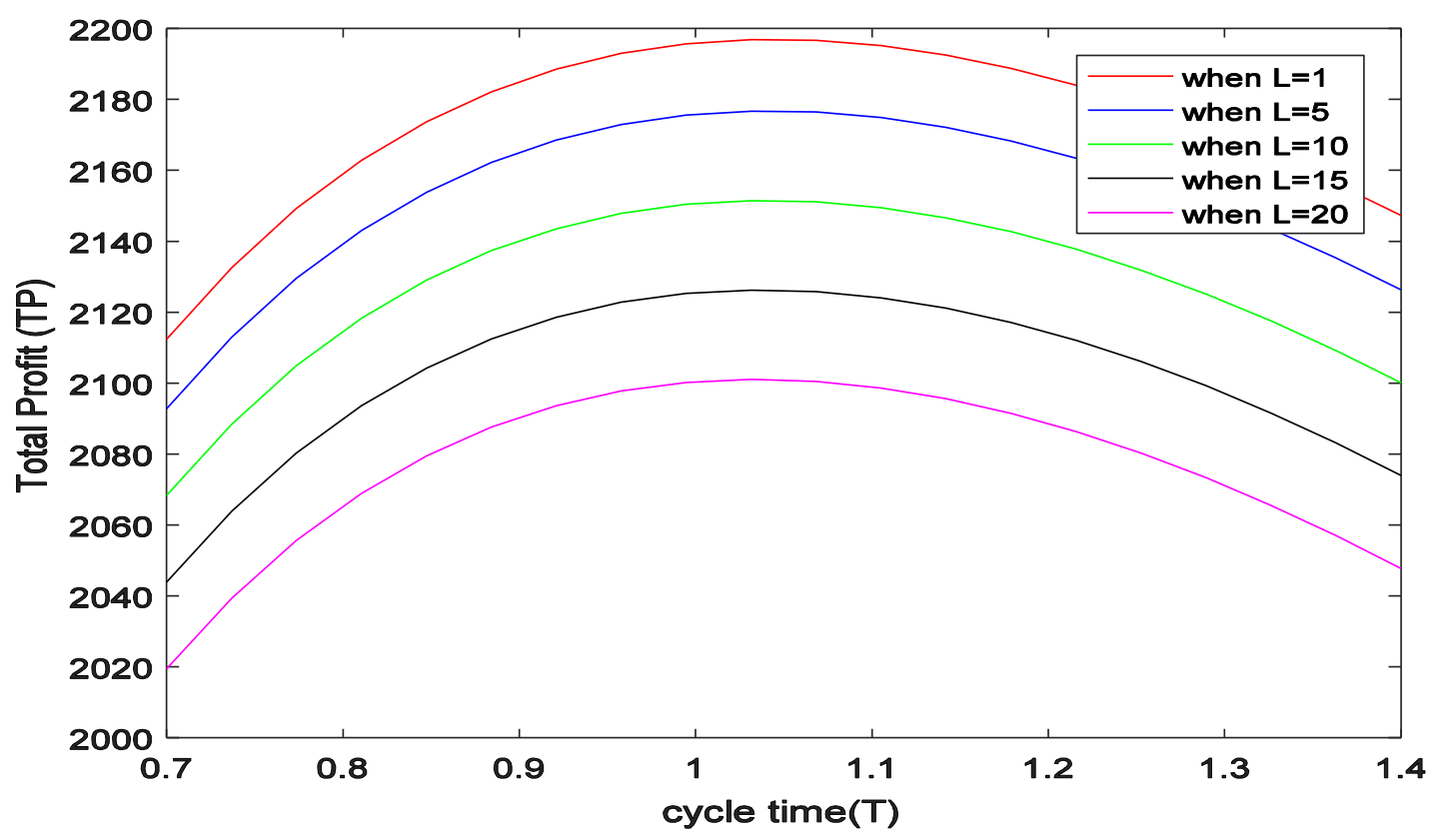

FiguRE 7. $\psi(p, T)$ with the changing of $L$ subject to cycle time $T$. 


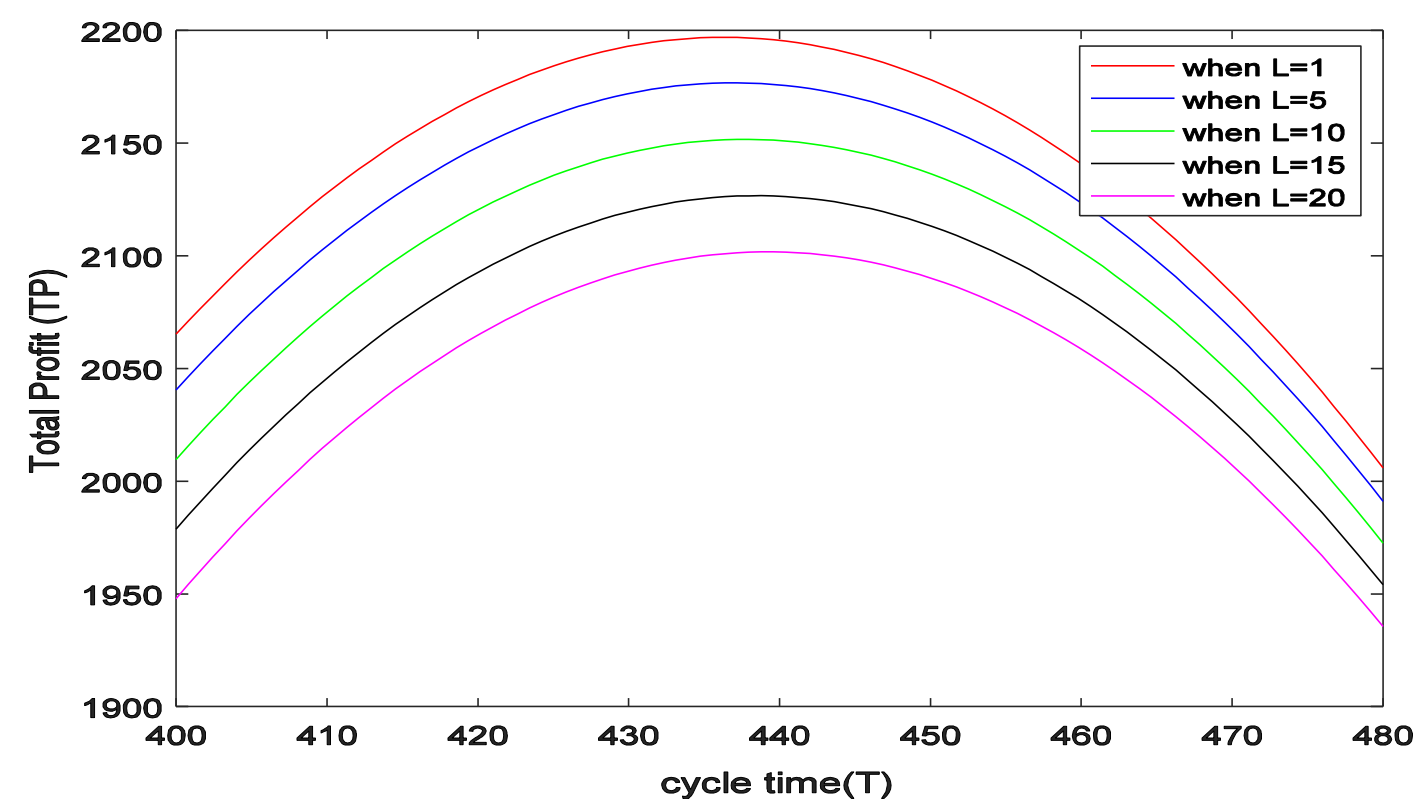

FiguRE 8. $\psi(p, T)$ with the changing of $L$ subject to selling price $p$.

happening because when the prepayment time is increasing, the retailer needs to wait for the products for a longer time and needs to pay some interest in taking that time.

Now, taking the same values of the given numerical Example 1, except for some variations given in the number of installments, some dramatic changes are noted in the graph of the profit function with reliant to the changed decision variables presented in Figures 9 and 10. The graphs show that when the number of installments is one, that is, when the retailer pays all the purchase cost when ordering the products, then the total profit of the retailer becomes significantly higher than others. The profit will decline with the rise in the number of installments as he receives a smaller discount rate.

Other parameters that play important roles in the model are the maximum lifetime of the products. Figures 11 and 12 show that when the maximum lifetime is one, i.e. $m=1$, the total profit for the retailer is minimum, while the total profit is maximum when $m$ is large (i.e. $m=20$ ). The result conforms to the study by Teng et al. [38] who observe that when the maximum lifetime increases, the total cost per unit time decreases and hence the total profit per unit time increases. A similar result is observed by Khan et al. [17].

The sensitivity analysis of the study is illustrated in Table 2 .

Observations: The following observations have been constructed on the results of Table 2 .

- The intensification of the parameter $a$ increases both the values of $p^{*}$ and total profit $\psi^{*}$. In contrast, $T^{*}$ decreases while the reduction of $T^{*}$ means that the retailer has to hold the products for a short period which will reduce holding costs. At the same time, the rise in selling price $p^{*}$ generates more profit.

- With the escalations on the value of the parameter $b$, the values of $p^{*}$ and total profit $\psi^{*}$ decline, but $T^{*}$ upsurges. The rise of $T^{*}$ means that the retailer has to hold the product for a more extended period which increases the holding cost. Alternatively, the reduction of $p^{*}$ indicates that the retailer has to sell products at lower prices. Hence, the total profit drops.

- The increase in $u$ and $p_{c}$ causes a decrease in $T^{*}$ and total profit $\psi^{*}$, but an increase in $p^{*}$. On the other hand, the rise in parameter $v$ and $h_{c}$ causes an upsurge in $p^{*}$ and $T^{*}$ but a reduction in total profit $\psi^{*}$.

- If the parameter $r$ upturns, then $p^{*}$ rises, and total profit $\psi^{*}$ falls while $T^{*}$ remains steady. When the parameter $\gamma$ increases, $p^{*}$ decreases, and the total profit $\psi^{*}$ increases, but $T^{*}$ remains the same. 


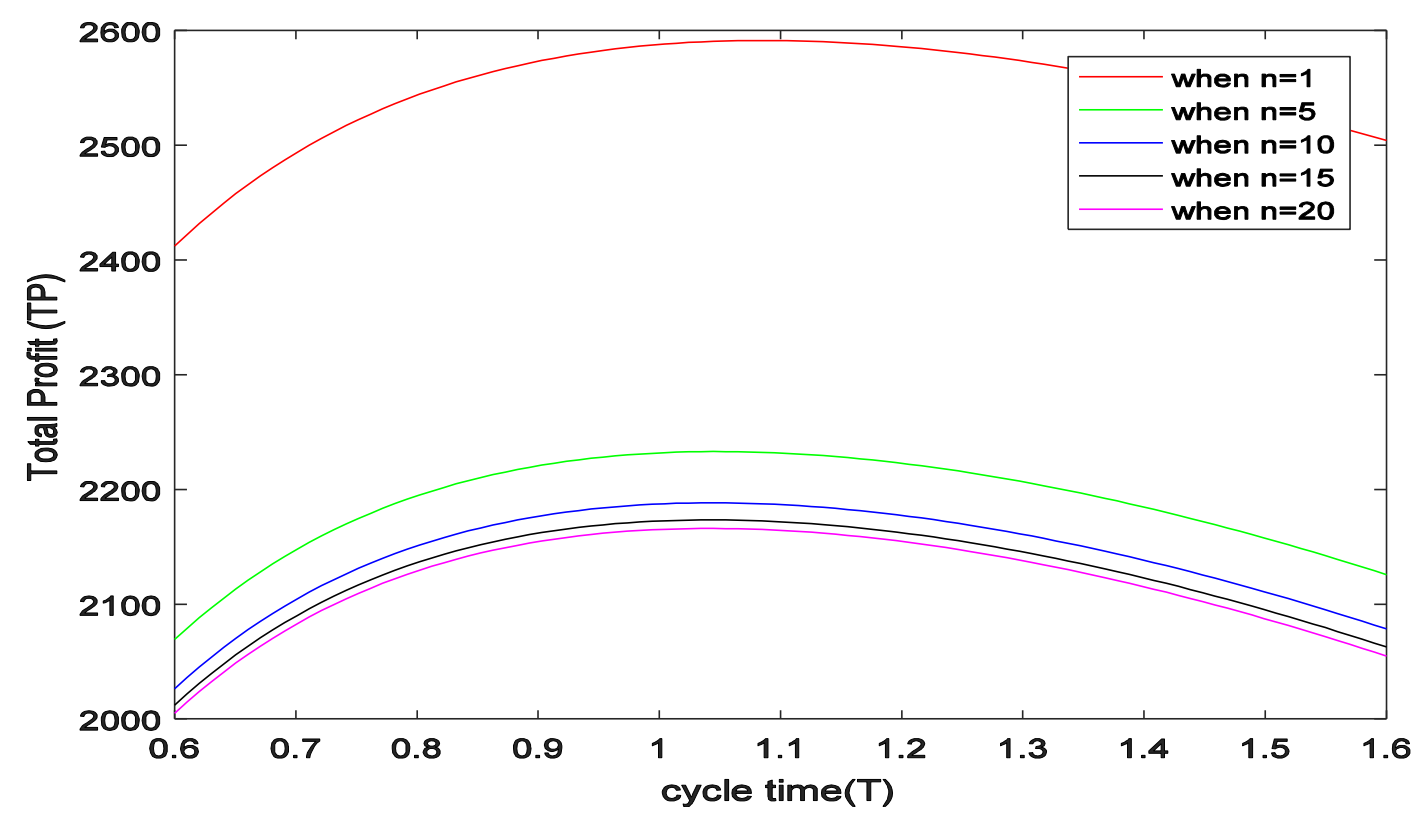

FiguRE 9. $\psi(p, T)$ with the changing of $n$ subject to cycle time $T$.

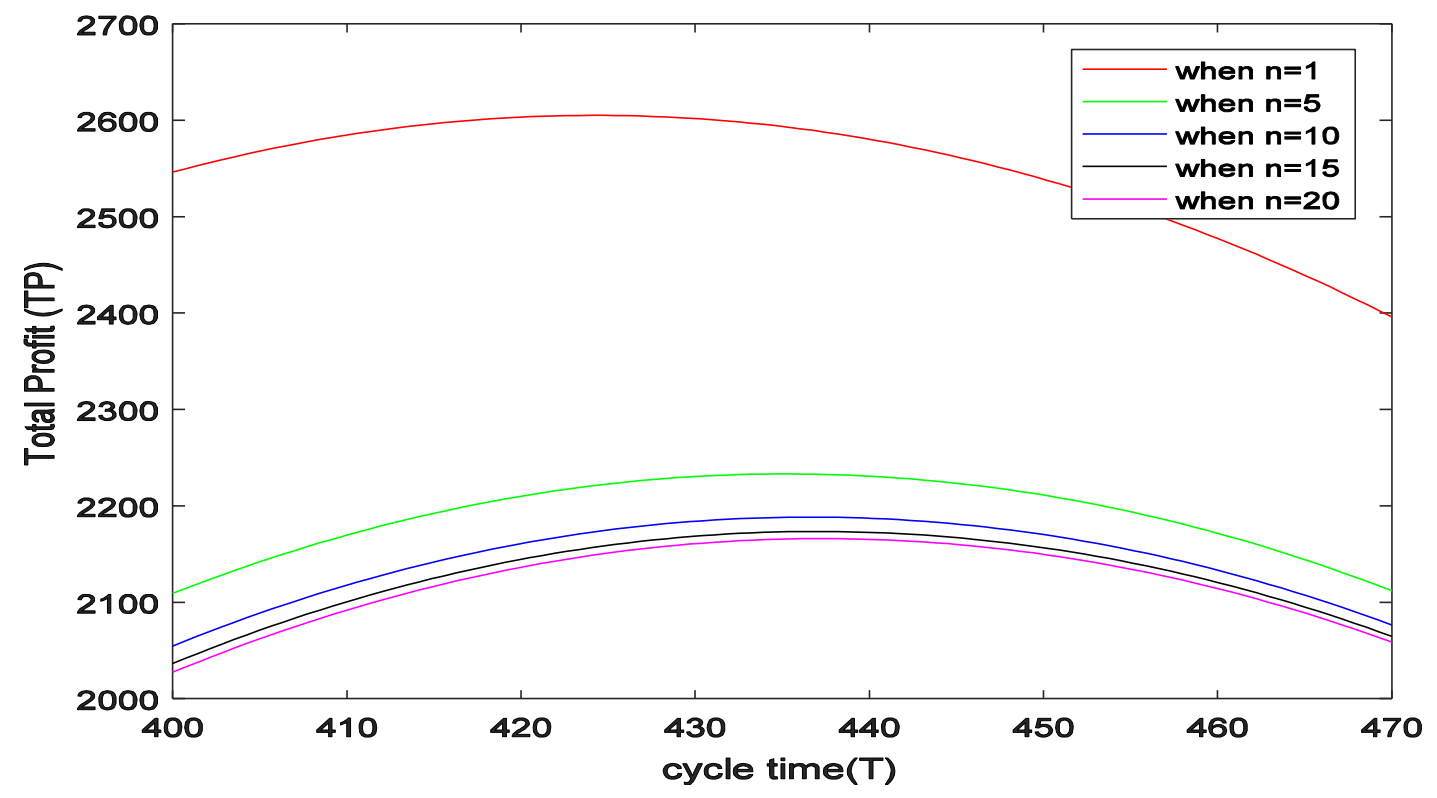

FIGURE 10. $\psi(p, T)$ with the changing of $n$ subject to selling price $p$. 


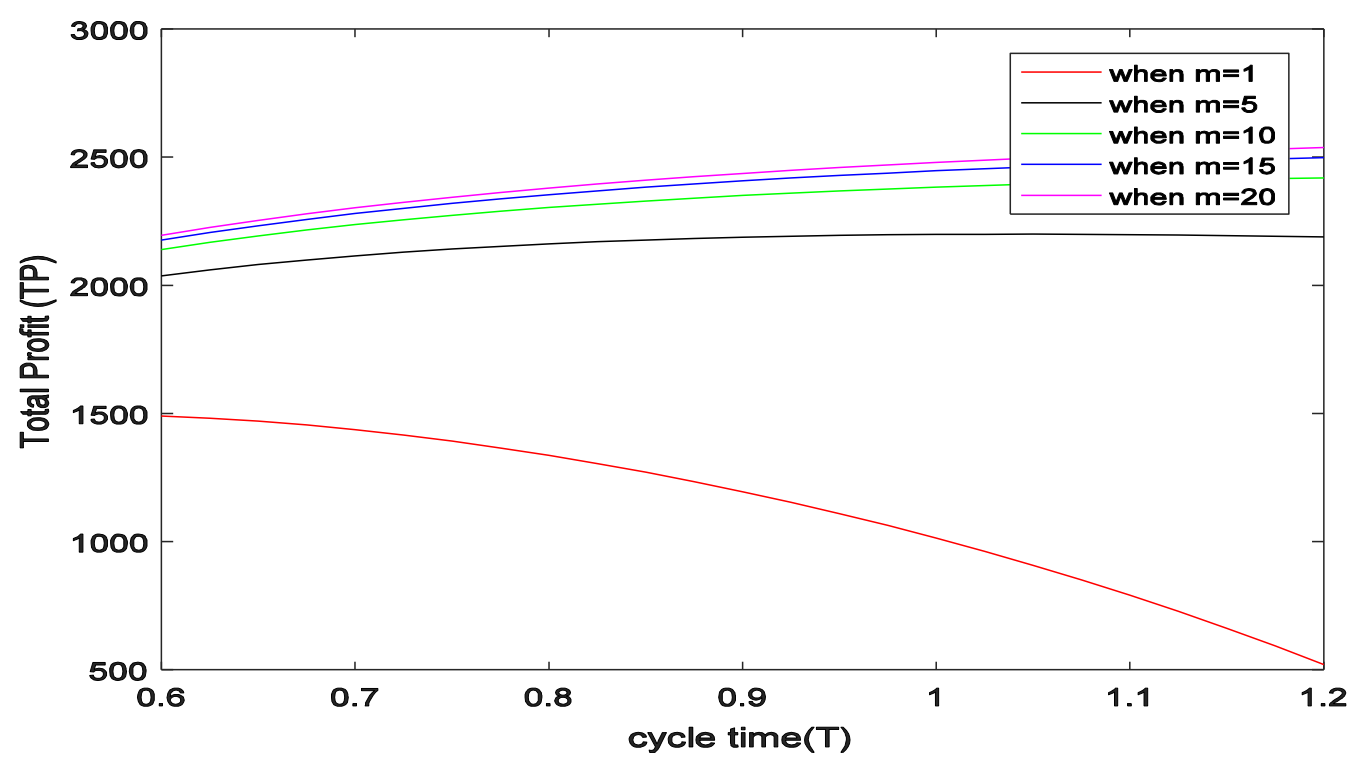

Figure 11. $\psi(p, T)$ with the changing of $m$ subject to cycle time $T$.

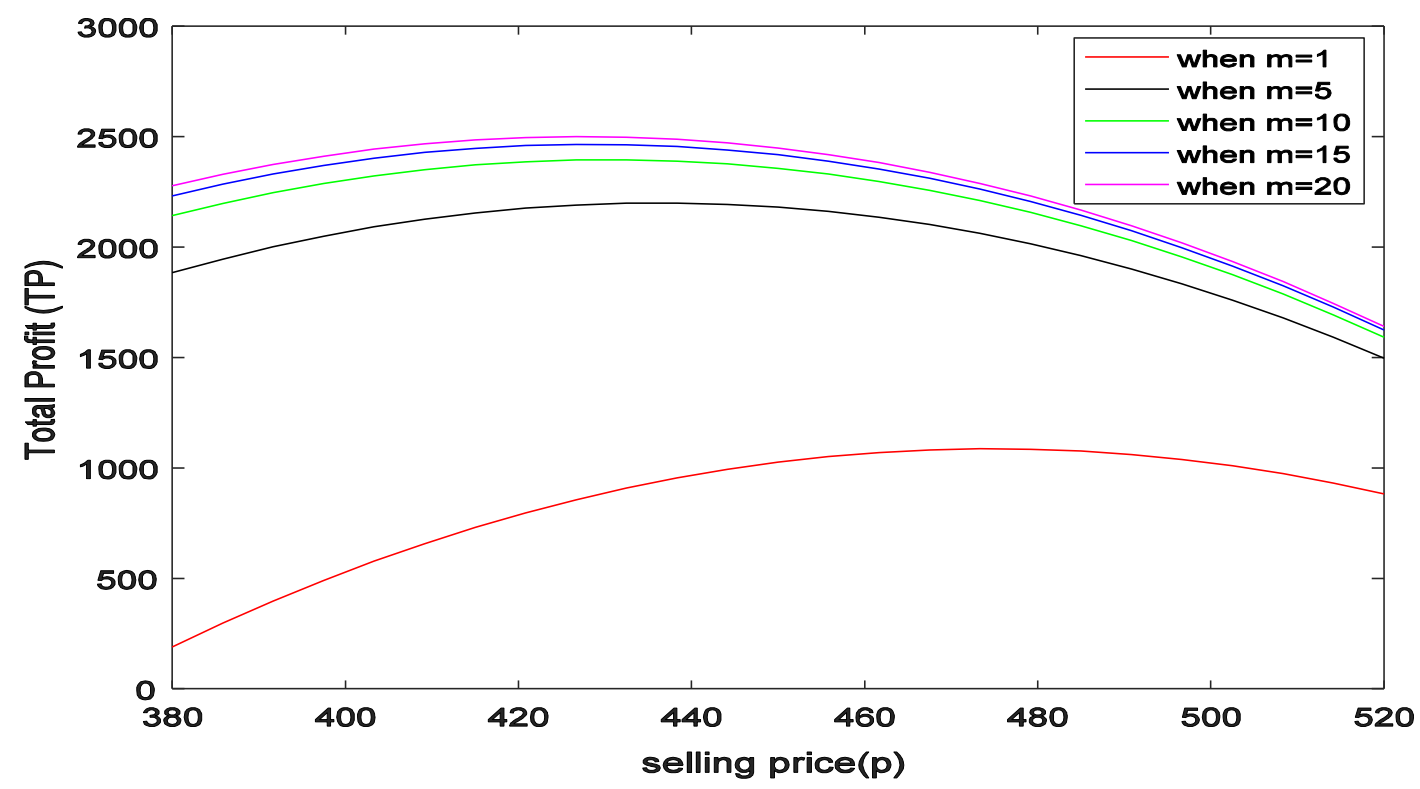

Figure 12. $\psi(p, T)$ with the changing of $m$ subject to selling price $p$. 
TABLE 2. Sensitivity analysis.

\begin{tabular}{|c|c|c|c|c|c|}
\hline Parameter & $\%$ changes & $p^{*}$ & $T^{*}$ & $\psi^{*}$ & $\%$ changes in $\psi^{*}$ \\
\hline \multirow[t]{4}{*}{$a$} & -20 & 380.117 & 1.281 & 607.286 & -66.38 \\
\hline & -10 & 407.957 & 1.136 & 1303.545 & -37.34 \\
\hline & 10 & 465.414 & 0.959 & 3264.856 & 45.47 \\
\hline & 20 & 494.570 & 0.898 & 4525.002 & 99.22 \\
\hline \multirow[t]{4}{*}{$b$} & -20 & 510.506 & 0.965 & 4070.627 & 82.45 \\
\hline & -10 & 469.302 & 0.998 & 3004.860 & 35.49 \\
\hline & 10 & 409.830 & 1.078 & 1559.371 & -27.29 \\
\hline & 20 & 387.819 & 1.127 & 1066.479 & -48.29 \\
\hline \multirow[t]{4}{*}{$u$} & -20 & 436.403 & 1.041 & 2195.865 & 0.38 \\
\hline & -10 & 436.449 & 1.038 & 2193.146 & 0.16 \\
\hline & 10 & 436.540 & 1.033 & 2187.731 & -0.27 \\
\hline & 20 & 436.586 & 1.030 & 2185.036 & -0.48 \\
\hline \multirow[t]{4}{*}{$v$} & -20 & 436.493 & 1.036 & 2191.049 & 3.29 \\
\hline & -10 & 436.494 & 1.036 & 2190.741 & 1.58 \\
\hline & 10 & 436.496 & 1.035 & 2190.128 & -1.62 \\
\hline & 20 & 436.497 & 1.034 & 2189.822 & -3.12 \\
\hline \multirow[t]{4}{*}{$r$} & -20 & 436.479 & 1.035 & 2190.939 & -0.03 \\
\hline & -10 & 436.487 & 1.035 & 2190.687 & -0.04 \\
\hline & 10 & 436.502 & 1.035 & 2190.182 & -0.06 \\
\hline & 20 & 436.510 & 1.035 & 2189.930 & -0.07 \\
\hline \multirow[t]{4}{*}{$\gamma$} & -20 & 436.479 & 1.035 & 2190.939 & -0.07 \\
\hline & -10 & 436.487 & 1.035 & 2190.687 & -0.06 \\
\hline & 10 & 436.502 & 1.035 & 2190.182 & -0.04 \\
\hline & 20 & 436.510 & 1.035 & 2189.930 & -0.03 \\
\hline \multirow[t]{4}{*}{$p_{c}$} & -20 & 409.664 & 1.060 & 3150.914 & 40.91 \\
\hline & -10 & 423.045 & 1.044 & 2652.187 & 19.55 \\
\hline & 10 & 450.037 & 1.034 & 1765.477 & -17.92 \\
\hline & 20 & 463.701 & 1.041 & 1377.292 & -34.08 \\
\hline \multirow[t]{4}{*}{$h_{c}$} & -20 & 436.401 & 1.042 & 2196.486 & 3.72 \\
\hline & -10 & 436.448 & 1.038 & 2193.454 & 1.80 \\
\hline & 10 & 436.541 & 1.032 & 2187.427 & -1.83 \\
\hline & 20 & 436.588 & 1.029 & 2184.430 & -3.56 \\
\hline
\end{tabular}

\section{Managerial insights}

Most products have an increasing deterioration rate over time and will be totally deteriorated at the end of their lifetime (i.e., expiration date). This study provides important managerial insights when the effect of price-dependent demand and advance payments with discount are considered:

- The time range for the retailer for advance payment has a significant effect on the total profit. For a longer advanced payment time, the retailer needs to pay some interest. Therefore, negotiating a shorter payment time with the current supplier is beneficial for a retailer.

- The number of installments (payments) also has a significant effect on the total profit. The highest profit occurs when the number of installments is one, that is, the retailer will pay all of the purchase cost while ordering the products because he receives the highest discount rate, which depends on the number of the installments.

- The product's maximum lifetime also influences the total profit. A shorter lifetime means the customers need to buy those products more frequently, hence, more profitable for a retailer. 
- Finally, the purchasing cost per unit product and the demand function significantly influences the total profit. Therefore, a retailer should search for the product with a lower purchasing cost and seek to set an optimal selling price to attract more demand.

\section{Conclusion}

In this study, a deteriorating item EOQ model is developed considering product life cycle and time reliant deterioration. At the maximum lifetime, the items fully deteriorate and have no value. The concept of advance payments with equal installments is also introduced. The supplier also provides a price discount when the retailer prepays some portion of the purchase cost before the delivery time, while another discount approach is applied with a single payment before receiving the products. In this case, the second discount approach provides a better result because the retailer does not need to pay interest for a long time. Yet at the same time, the first approach of the proposed model also exhibits some managerial insights for the retailer who cannot pay in single installments before receiving products. Selling price-sensitive demand with a realistic linear holding cost is considered where the holding cost comprises a constant part and a variable part, and this idea of holding cost extends that of Teng et al. [38], who considered a constant holding cost. The elasticity of some important factors is studied in the sensitivity analysis section. The effect of some parameters is carefully examined, and some valuable theoretical derivations have been found from the model. The total profit is significantly influenced by the prepayment time, the number of prepaying installments, and the product life cycle.

This study is limited by assuming product price as the sole influence of demand. Therefore, future research direction can incorporate other influencing factors such as stock level (see [20,31]) and advertisement policy (see [24]). In addition, further studies can incorporate the effect of wastes disposal (see [15]) or greenhouse gas emissions from its disposal (see [13]).

\section{Appendix A.}

Proof of Theorem 4.1. Considering equation (4.1) to state

$$
\begin{aligned}
F(T)= & \frac{O}{T^{2}}+p_{c} D \mu_{1}\left(1+\frac{n+1}{2 n} \gamma L r-\frac{x}{n}\right) \\
& +h_{c} D\left[\frac{u}{4}\left\{2(1+m) \mu_{1}-1\right\}+v\left\{\frac{1}{36 T^{2}}\left(5 \mu_{2}-5 \mu_{3}-2 \mu_{4} T\right)-\frac{(1+m)^{2}}{6} \mu_{1}\right\}\right] .
\end{aligned}
$$

Then

$$
F(m)=\frac{1}{m^{2}}\left[O-p_{c} D(1+m) \eta_{1}\left(1+\frac{n+1}{2 n} \gamma L r-\frac{x}{n}\right)-\frac{h_{c} D}{2}\left\{\frac{u \eta_{2}}{2}-\frac{v \eta_{3}}{3}\right\}\right]
$$

To find the value of $\mu_{1}$, here we use L'Hospital's Rule. Let us calculate

$$
\begin{aligned}
& \lim _{T \rightarrow 0} \mu_{1} \\
& \lim _{T \rightarrow 0}\left[(1+m)\left\{\frac{1}{T^{2}} \ln \left(\frac{1+m}{1+m-T}\right)-\frac{1}{(1+m-T) T}\right\}\right] \\
& \quad=(1+m) \lim _{T \rightarrow 0}\left[\frac{(1+m-T) \ln \left(\frac{1+m}{1+m-T}\right)-T}{(1+m-T) T^{2}}\right] \\
& \quad=(1+m) \lim _{T \rightarrow 0}\left[\frac{-1}{2 T+2 m T-3 T^{2}} \ln \left((1+m)(1+m-T)^{-1}\right)\right]
\end{aligned}
$$


S1086

A.H. MD MASHUD ET AL.

$$
\begin{aligned}
& =(1+m) \lim _{T \rightarrow 0}\left[\frac{-1}{(2+2 m-6 T)(1+m-T)}\right] \\
& =\frac{-1}{2(1+m)} .
\end{aligned}
$$

Using (A.3) in (A.1), we get

$$
F(0)=\lim _{T \rightarrow 0}\left[\begin{array}{l}
\frac{-p_{c} D}{2(1+m)}\left(1+\frac{n+1}{2 n} \gamma L r-\frac{x}{n}\right)-\frac{h_{c} u D}{2}+\frac{h_{c} v D}{12}(1+m) \\
+\frac{h_{c} v D}{36 T^{2}}\left\{5(1+m)^{3}-5(1+m) \frac{1}{(1+m-T)^{-2}}\right\} \\
-\frac{h_{c} v D}{18 T}(1+m-T)(5+5 m-4 T)
\end{array}\right]=\infty .
$$

From (4.2), let us consider

$$
\rho(T)=(1+m) \ln \left(\frac{1+m}{1+m-T}\right)-T
$$

It is obvious that $\rho(0)=0$.

Now $\frac{\mathrm{d} \rho(T)}{\mathrm{d} T}=\frac{1+m}{1+m-T}-1$, which is greater than zero, for all values of $T>0$.

It indicates that despite $T>0, \rho(T)>0$.

As a result,

$$
\frac{(1+m)}{T} \ln \left(\frac{1+m}{1+m-T}\right)>1, \quad \text { for all } T>0
$$

Simplifying (4.2) and using (A.5), we get

$$
\begin{aligned}
\frac{\mathrm{d} F(T)}{\mathrm{d} T} \leq & -p_{c} D\left(1+\frac{n+1}{2 n} \gamma L r-\frac{x}{n}\right)\left[\frac{2}{T^{2}}-\frac{(1+m)(2+2 m-3 T)}{(1+m-T)^{2} T^{2}}\right] \\
& -\frac{h_{c} u D(1+m)}{2}\left[\frac{2}{T^{2}}-\frac{(1+m)(2+2 m-3 T)}{(1+m-T)^{2} T^{2}}\right]-\frac{h_{c} v D(1+m)^{2}}{6}\left[\frac{2}{T^{2}}-\frac{(1+m)(2+2 m-3 T)}{(1+m-T)^{2} T^{2}}\right] \\
& +\frac{2 h_{c} v D}{9}-\frac{10 h_{c} v D(1+m)^{3}}{9 T^{3}} \\
= & \frac{(1+m-2 T)}{(1+m-T)^{2} T}\left[p_{c} D\left(1+\frac{n+1}{2 n} \gamma L r-\frac{x}{n}\right)+\frac{h_{c} D(1+m)}{6}\{3 u+v(1+m)\}\right] \\
& -\frac{2 h_{c} v D}{9}\left\{\frac{5(1+m)^{3}}{T^{3}}-1\right\} \\
& <0 \text { if } \frac{(1+m-2 T)}{(1+m-T)^{2} T}\left[p_{c} D\left(1+\frac{n+1}{2 n} \gamma L r-\frac{x}{n}\right)+\frac{h_{c} D(1+m)}{6}\{3 u+v(1+m)\}\right]<0 .
\end{aligned}
$$

If $W \geq 0$, then $F(m) \geq 0$. For all $T<m$ with the help of equation (A.4) and (A.6) one can write $F(T)>0$. Hence, the function $\psi(p, T)$ is increasing in $T$, and at the same time maximized at $T^{*}=m$. Finally, when $W<0$, then $F(m)<0$. By putting on the Mean Value Theorem into $F(0)=\infty$ and $F(m)<0$, there occurs a unique value of $T$ say, $T^{*}$ for which $F\left(T^{*}\right)=0$ and consequently $\psi(p, T)$ is maximized at unique $T^{*} \in(0, m)$, which concludes the proof. 


\section{Appendix B.}

Proof of Theorem 4.2. Performing the first-order and second-order partial derivatives of $\psi(p, T)$ in $(3.10)$ with regard to $p$, we get

$$
\begin{aligned}
\frac{\partial \psi}{\partial p}= & (a-2 b p)+p_{c} b(1+m)\left(1+\frac{n+1}{2 n} \gamma L r-\frac{x}{n}\right) \frac{1}{T} \varphi \\
& +h_{c} b\left[\begin{array}{l}
u\left\{\frac{(1+m)}{2 T} \varphi+\frac{1}{4}(-2-2 m+T)\right\} \\
+v\left\{\frac{1}{36 T}\left((1+m-T)^{2}(5+5 m+4 T)-5(1+m)^{3}\right)+\frac{(1+m)^{2}}{6 T} \varphi\right\}
\end{array}\right]
\end{aligned}
$$

and

$$
\frac{\partial^{2} \psi}{\partial p^{2}}=-2 b<0
$$

Therefore the concavity of the function $\psi(p, T)$ exists in $p$ and gives a unique maximum solution $p^{*}$. This completes the proof.

Acknowledgements. We want to thank the editor and reviewers for their contributions in improving the quality of the paper. This paper is funded by the UGC-IRT research grant 2019-2020 (Code 5921) from Hajee Mohammad Danesh Science and Technology University, Dinajpur-5200, Bangladesh.

\section{REFERENCES}

[1] S.P. Aggarwal and C.K. Jaggi, Ordering policies of deteriorating items under permissible delay in payments. J. Oper. Res. Soc. 46 (1995) 658-662.

[2] H.K. Alfares and A.M. Ghaithan, Inventory and pricing model with price-dependent demand, time-varying holding cost, and quantity discounts. Comput. Ind. Eng. 94 (2016) 170-177.

[3] S.C. Chen and J.T. Teng, Retailer's optimal ordering policy for deteriorating items with maximum lifetime under supplier's trade credit financing. Appl. Math. Model. 38 (2014) 4049-4061.

[4] S.C. Chen, J. Min, J.T. Teng and F. Li, Inventory and shelf-space optimization for fresh produce with expiration date under freshness-and-stock-dependent demand rate. J. Oper. Res. Soc. 67 (2016) 884-896.

[5] Y. Chen, C. Chen, F. Chiu, and J. Lian, Applying the bootstrap method to newsvendor model incorporating group buying for optimal price discount and order quantity. Kybernetes 46 (2017) 1692-1705.

[6] C.Y. Dye and T.P. Hsieh, Deterministic ordering policy with price- and stock-dependent demand under fluctuating cost and limited capacity. Expert Syst. App. 38 (2011) 14976-14983.

[7] S.K. Goyal, Economic order quantity under conditions of permissible delay in payments. J. Oper. Res. Soc. 36 (1985) 335-338.

[8] R.K. Gupta, A.K. Bhunia and S.K. Goyal, An application of genetic algorithm in solving an inventory model with advance payment and interval valued inventory costs. Math. Comput. Model. 49 (2009) 893-905.

[9] A. Guria, B. Das, S. Mondal and M. Maiti, Inventory policy for an item with inflation induced purchasing price, selling price and demand with immediate part payment. Appl. Math. Model. 37 (2013) 240-257.

[10] M.R. Hasan and A.H.M. Mashud, An economic order quantity model for decaying products with the frequency of advertisement, selling price and continuous time dependent demand under partially backlogged shortage. Int. J Suppl. Oper. Manage. 6 (2019) $296-314$.

[11] K.L. Hou and L.C. Lin, An EOQ model for deteriorating items with price- and stock- dependent selling rates under inflation and time value of money. Int. J. Syst. Sci. 37 (2006) 1131-1139.

[12] M.W. Iqbal and B. Sarkar, Application of normalized lifetime-dependent selling-price in a supply chain model. Int. J. Appl. Comput. Math. 4 (2018) 124.

[13] M.W. Iqbal and B. Sarkar, Recycling of lifetime dependent deteriorated products through different supply chains. RAIRO:OR 53 (2019) 129-156.

[14] M.W. Iqbal and B. Sarkar, Application of preservation technology for lifetime dependent products in an integrated production system. J. Ind. Manage. Optim. 16 (2020) 141-167.

[15] M.W. Iqbal, Y.C. Kang and H.W. Jeon, Zero waste strategy for green supply chain management with minimization of energy consumption. J. Cleaner Prod. 245 (2020) 118827.

[16] O. Jadidi, M.Y. Jaber and S. Zolfaghari, Joint pricing and inventory problem with price dependent stochastic demand and price discounts. Comput. Ind. Eng. 114 (2017) 45-53.

[17] M.A.A. Khan, A.A. Shaikh, G.C. Panda, I. Konstantaras and A.A. Taleizadeh, Inventory system with expiration date: Pricing and replenishment decisions. Comput. Ind. Eng. 132 (2019) 232-247. 
[18] M.A.A. Khan, A.A. Shaikh, G.C. Panda and I. Konstantaras, Two-warehouse inventory model for deteriorating items with partial backlogging and advance payment scheme. RAIRO:OR 53 (2019) 1691-1708.

[19] M.A.A. Khan, A.A. Shaikh, I. Konstantaras, A.K. Bhunia and L.E. Cárdenas-Bárron, Inventory models for perishable items with advanced payment, linearly time-dependent holding cost and demand dependent on advertisement and selling price. Int. J. Prod. Econ. 230 (2020) 107804.

[20] M.A.A. Khan, A.A. Shaikh, G.C. Panda, I. Konstantaras and L.E. Cárdenas-Barrón, The effect of advance payment with discount facility on supply decisions of deteriorating products whose demand is both price and stock dependent. Int. Trans. Oper. Res. 27 (2020) 1343-1367.

[21] M.A.A. Khan, A.A. Shaikh, G.C. Panda, A.K. Bhunia and I. Konstantaras, Non-instantaneous deterioration effect in ordering decisions for a two-warehouse inventory system under advance payment and backlogging. Ann. Oper. Res. 289 (2020) $243-275$.

[22] A.K. Maiti, M.K. Maiti and M. Maiti, Inventory model with stochastic lead-time and price dependent demand incorporating advance payment. Appl. Math. Model. 33 (2009) 2433-2443.

[23] A.H.M. Mashud, A deteriorating inventory model with different types of demand and fully backlogged shortages. Int. J. Logistics Syst. Manage. 36 (2020) 16-45.

[24] A.H.M. Mashud, M.R. Hasan, H.M. Wee and Y. Daryanto, Non-instantaneous deteriorating inventory model under the joined effect of trade-credit, preservation technology and advertisement policy. Kybernetes 49 (2019) 1645-1674.

[25] A.H.M. Mashud, M.A.A. Khan, M.S. Uddin and M.N. Islam, A non-instantaneous inventory model having different deterioration rates with stock and price dependent demand under partially backlogged shortages. Uncertain Supply Chain Manage. 6 (2018) 49-64.

[26] A.H.M. Mashud, M.S. Uddin and S.S. Sana, A two-level trade-credit approach to an integrated price-sensitive inventory model with shortages. Int. J. Comput. Appl. Math. 5 (2019) 121.

[27] A.H.M. Mashud, H.M. Wee and C.V. Huang, Preservation technology investment, trade credit and partial backordering model for a non-instantaneous deteriorating inventory. RAIRO:OR (Forthcoming article), DOI: 10.1051/ro/2019095.

[28] A.H.M. Mashud, H.M. Wee, B. Sarkar and Y.H. Chiang Li, A sustainable inventory system with the advanced payment policy and trade-credit strategy for a two- warehouse inventory system. Kybernetes, (2020) https://doi.org/10.1108/ K-01-2020-0052

[29] B. Pal, S.S. Sana and K. Chaudhuri, A stochastic production inventory model for deteriorating items with products' finite life-cycle. RAIRO:OR 51 (2017) 669-684.

[30] G.C. Panda, M.A.A. Khan and A.A. Shaikh, A credit policy approach in a two-warehouse inventory model for deteriorating items with price- and stock-dependent demand under partial backlogging. J. Ind. Eng. Int. 15 (2018) 147-170.

[31] A.A. Shaikh, A.H.M. Mashud, M.S. Uddin and M.A.A. Khan, Non-instantaneous deterioration inventory model with price and stock dependent demand for fully backlogged shortages under inflation. Int. J. Bus. Forecasting Marketing Intell. 3 (2017) $152-164$.

[32] A.A. Shaikh, M.A.A. Khan, G.C. Panda and I. Konstantaras, Price discount facility in an EOQ model for deteriorating items with stock-dependent demand and partial backlogging. Int. Trans. Oper. Res. 26 (2019) 1365-1395.

[33] A.A. Shaikh, S.C. Das, A.K. Bhunia, G.C. Panda and M.A.A. Khan, A two-warehouse EOQ model with interval-valued inventory cost and advance payment for deteriorating item under particle swarm optimization. Soft Comput. 23 (2019) 1353113546.

[34] A.A. Taleizadeh, An economic order quantity model for deteriorating item in a purchasing system with multiple prepayments. Appl. Math. Model. 38 (2014) 5357-5366.

[35] A.A. Taleizadeh, Lot-sizing model with advance payment pricing and disruption in supply under planned partial backordering. Int. Trans. Oper. Res. 24 (2017) 783-800.

[36] A.A. Taleizadeh, I. Stojkovska and D.W. Pentico, An economic order quantity model with partial backordering and incremental discount. Comput. Ind. Eng. 82 (2015) 21-32.

[37] A.A. Taleizadeh, S. Tavakoli and L.A. San-José, A lot sizing model with advance payment and planned backordering. Ann. Oper. Res. 271 (2018) 1001-1022.

[38] J.T. Teng, L.E. Cárdenas-Barrón, H.J. Chang, J. Wu and Y. Hu, Inventory lot-size policies for deteriorating items with expiration dates and advance payments. Appl. Math. Model. 40 (2016) 8605-8616.

[39] S. Tiwari, L.E. Cárdenas-Barrón, M. Goh and A.A. Shaikh, Joint pricing and inventory model for deteriorating items with expiration dates and partial backlogging under two-level partial trade credits in supply chain. Int. J. Prod. Econ. 200 (2018) $16-36$.

[40] W.C. Wang, J.T. Teng and K.R. Lou, Seller's optimal credit period and cycle time in a supply chain for deteriorating items with maximum lifetime. Eur. J. Oper. Res. 232 (2014) 315-321.

[41] J. Wu, L.Y. Ouyang, L.E. Cárdenas-Barrón and S.K. Goyal, Optimal credit period and lot size for deteriorating items with expiration dates under two-level trade credit financing. Eur. J. Oper. Res. 237 (2014) 898-908.

[42] P.C. Yang, H.M. Wee, S.L. Chung and Y.Y. Huang, Pricing and replenishment strategy for a multi-market deteriorating product with time-varying and price-sensitive demand. J. Ind. Manage. Optim. 9 (2013) 769-787. 